\title{
Sundering of earthworms by the Fairy Pitta (Pitta nympha): an unexplored strategy of prey preparation for brood provisioning by avian vermivores
}

\author{
Jinseok Park ${ }^{1}$ (D) Woojoo $\mathrm{Kim}^{1}$ (D) $\cdot$ Jungmoon Ha ${ }^{1}$ (D) Sang-im Lee ${ }^{2}$ (D) Piotr Grzegorz Jablonski ${ }^{1,3}$ (D)
}

Received: 20 April 2021 / Revised: 25 September 2021 / Accepted: 4 December 2021 / Published online: 18 December 2021

(c) The Author(s) 2021

\begin{abstract}
Ecological specialists utilize a restricted range of resources and have evolved adaptations to exploit their specialized resources. For example, avian insectivores that feed nestlings with grasshoppers, beetles, or moths perform insect prey preparation before feeding nestlings so that the nestlings are able to swallow the prey. This behavior is generally not expected for soft prey such as earthworms. However, an overview of photographic evidence available online suggested that earthworms are sundered by parents before bringing the prey to the nestlings in a range of species from several families of vermivores worldwide. Reports on the provisioning of nestlings by the vermivores are relatively scant and no report on earthworm sundering has been published. We studied earthworm sundering performed by parents provisioning their broods at four nests of the Fairy Pitta in Korea. The birds sundered earthworms more often when nestlings were smaller and when the earthworm was longer. This is the first quantitative description of earthworm sundering in avian vermivores. We present and evaluate four hypotheses for the function of sundering: provisioning of small nestlings, decreased detectability, hunting multiple prey, and transport of prey. Among these, provisioning of small nestlings seems the most feasible explanation of sundering by the Fairy Pitta as sundering the earthworm allows parents to efficiently provision the younger/smaller nestlings who would have difficulties swallowing unsundered earthworms. This specialized prey preparation technique of vermivores suggests a tight adaptive match between their parental behaviors and their diet (vermivory).
\end{abstract}

Keywords Fairy Pitta $\cdot$ Avian vermivores $\cdot$ Earthworm $\cdot$ Sundering

\section{Zusammenfassung}

Das Zerteilen von Regenwürmern durch Nymphenpittas Pitta nympha: eine unerforschte Strategie der Beutebearbeitung zur Nestlingsversorgung bei einer vermivoren Vogelart.

Ökologische Spezialisten nutzen ein begrenztes Ressourcenspektrum und haben Anpassungen zur Verwertung dieser speziellen Ressourcen entwickelt. So bearbeiten beispielsweise insektivore Vögel, welche ihre Nestlinge mit Grashüpfern, Käfern oder Nachtfaltern versorgen, diese Insekten vor dem Verfüttern, damit die Nestlinge die Beute herunterschlucken

Communicated by F. Bairlein.

Sang-im Lee

sangim@dgist.ac.kr

Piotr Grzegorz Jablonski

piotrjab@behecolpiotrsangim.org

1 Laboratory of Behavioral Ecology and Evolution, School of Biological Sciences, Seoul National University, Seoul 08826, South Korea

2 Department of New Biology, Laboratory of Integrative Animal Ecology, DGIST, Daegu 42988, South Korea

3 Museum and Institute of Zoology, Polish Academy of Sciences, Wilcza 64, Warsaw, Poland 
können. Bei weichen Beutetieren wie etwa Regenwürmern ist ein solches Verhalten in der Regel nicht zu erwarten. Eine Sichtung online verfügbarer Fotobelege legte allerdings nahe, dass bei einer Reihe von vermivoren Arten aus mehreren Familien weltweit Regenwürmer von den Elternvögeln zerteilt werden, bevor die Beute den Nestlingen übergeben wird. Berichte über die Nestlingsfütterung vermivorer Vögel sind relativ dünn gesät und es gibt keine Veröffentlichungen über das Zerteilen von Regenwürmern. An vier Nestern der Nymphenpitta in Korea untersuchten wir das Zerkleinern von Regenwürmern durch Elternvögel, die ihre Brut versorgten. Die Vögel zerteilten die Regenwürmer häufiger, solange die Nestlinge noch klein und wenn der Wurm länger war. Dies ist die erste quantitative Beschreibung des Zerteilens von Regenwürmern durch vermivore Vögel. Wir stellen vier Hypothesen über die Funktion des Zerteilens vor und diskutieren diese, nämlich: die Versorgung kleiner Nestlinge, verringerte Auffälligkeit, das Erjagen mehrerer Beutetiere sowie der Transport der Beute. Darunter scheint die Versorgung kleiner Nestlinge die plausibelste Erklärung für das Zerteilen bei den Nymphenpittas zu sein, denn die Zerkleinerung des Regenwurms ermöglicht es den Eltern, jüngere/kleinere Nestlinge effizient zu versorgen, die sonst Schwierigkeiten hätten, unzerteilte Regenwürmer hinunterzuschlucken. Diese spezialisierte Technik der Beutebearbeitung bei Vermivoren deutet auf einen engen adaptiven Zusammenhang zwischen deren Brutfürsorgeverhalten und ihrer Ernährungsweise (Vermivorie) hin.

\section{Introduction}

Ecological specialists can be defined as a species occupying a narrow niche or using a restricted range of resources (Irschick et al. 2005), which leads to the evolution of unique adaptations for the exploitation of their specialized resources (Futuyma and Moreno 1988). One form of specialization is diet specialization. Diet specialization that involves feeding on earthworms (vermivory) is observed in a range of avian species from several families worldwide, such as pittas (Erritzoe 2020a; Winkler et al. 2020), antpittas (Grallariidae: Schulenberg and Kirwan 2020), and thrushes (Turdidae: Montgomerie and Weatherhead 1997; Collar 2020; Collar et al. 2020; del Hoyo et al. 2020; Vanderhoff et al. 2020). In those taxa, earthworms account for the largest proportion of their nestlings' diet (e.g., Gruar et al. 2003; Lopes et al. 2016; Park et al. own unpublished data), but not many studies focused on the prey handling behaviors by vermivores that consume earthworms (one example is in Montgomerie and Weatherhead 1997).

The Fairy Pitta, Pitta nympha (Erritzoe 2020b), is one of those vermivores. It is a ground forager with unique dietary specializations that may require special behavioral adaptations. The diet of young nestlings consists of over $80 \%$ of earthworms (Lin et al. 2007; Kim et al. 2012; Jiang et al. 2017; Park et al. own unpublished data). Photographic evidence (Park 2014) suggested that pittas regularly sunder earthworms before carrying them to the nest to feed their nestlings. Although prey preparation by parents before feeding nestlings has been analyzed in birds (Kaspari 1990, 1991; Sodhi 1992; Barba et al. 1996; Banbura et al. 1999; Ponz et al. 1999; Rands et al. 2000; Steen et al. 2010), the earthworm sundering behavior has never been studied. Unlike prey in those previous studies, earthworms are soft prey items that may not require the removal of parts that may be difficult to swallow by nestlings.
Sundering of earthworms seems to have evolved independently in at least several different families of vermivorous birds. An overview of photographic archives at the Macaulay library at the Cornell Lab of Ornithology suggests that sundering occurs in other pittas such as Pitta moluccensis (Fig. 1A; Erritzoe 2020a), antpittas (Grallaridae) such as Grallaria alleni (Fig. 1B; Schulenberg and Kirwan 2020), and thrushes (Turdidae) such as Turdus migratorius (Fig. 1C; Vanderhoff et al. 2020), Turdus pilaris (Fig. 1D; Collar 2020), Zoothera dauma (Fig. 1E; Collar et al. 2020). The aim of the study was to describe the behavior of prey sundering by the Fairy Pitta and to evaluate hypotheses about the functions of this behavior in pittas and other species of vermivorous birds. We consider several mutually non-exclusive hypotheses for the adaptive function of earthworms sundering:

1. Provisioning of small nestlings hypothesis This hypothesis proposes that the smaller/younger nestlings have difficulties swallowing a whole large earthworm and sundering the earthworm into sections allows parents to provision the younger nestling with one easy-to-swallow section at a time. The hypothesis is consistent with interpretation of studies of prey preparation in other birds (e.g., Barba et al. 1996; Banbura et al. 1999; Ponz et al. 1999). An additional benefit of sundering, especially for young nestlings, may be an increase in the digestibility of the prey (Kaspari 1990, 1991). The provisioning of small nestlings hypothesis predicts that sundering should be more frequent for younger nestlings, as already shown in other species (Barba et al. 1996; Banbura et al. 1999; Ponz et al. 1999; Steen et al. 2010). The hypothesis also predicts that larger worms should be sundered more often and the sections of earthworms fed to younger nestlings should be shorter.

2. Decreased detectability hypothesis As sundered earthworms are easy for nestlings to swallow, sunder- 
Fig. 1 Photographic evidence for earthworm sundering in several species of avian vermivores. A blue-winged Pitta (Pitta moluccensis); B moustached Antpitta (Grallaria alleni); C American Robin (Turdus migratorius); $\mathbf{D}$ fieldfare, (Turdus pilaris); E scaly Thrush (Zoothera dauma). Arrows indicate the places where the earthworm was sundered. We used the following records from the Macaulay Library at the Cornell Lab of Ornithology: ML62187411, ML219545401, ML100337181, ML43163821, ML56759961
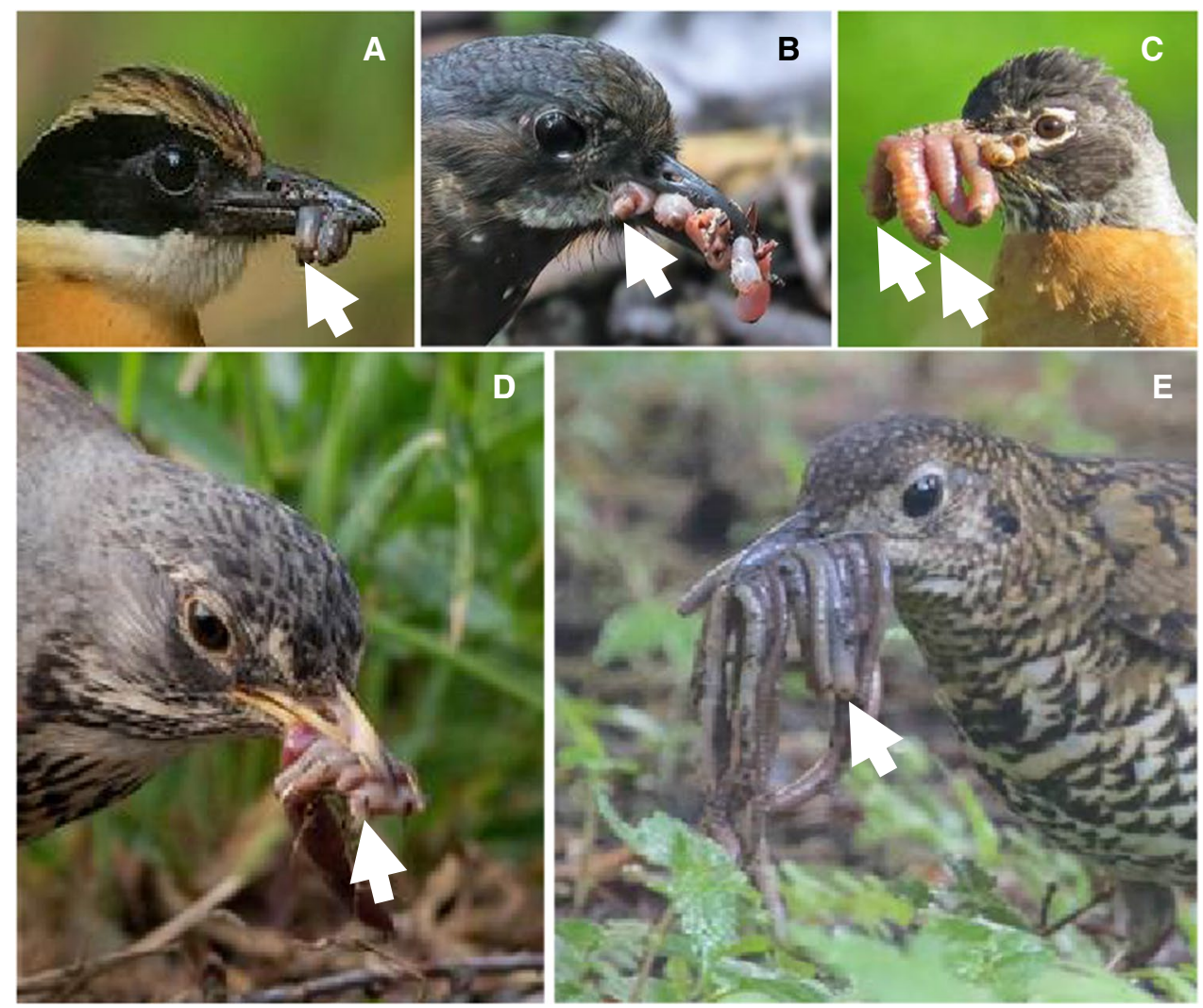

ing may reduce the duration of an adult perching at the nest entrance while feeding the nestlings (as in Online Resource 3, 4, 5). This may not only increase the efficiency of food provisioning (provisioning of small nestlings hypothesis), but it may also reduce the risk of detection by predators (decreased detectability hypothesis). The predictions are partly similar to the hypothesis (1) in that larger worms should be sundered more often. However, if we view this hypothesis from the life-history theory perspective and assume that brood value (in terms of parental fitness) increases with brood age (Winkler 1987; Montgomerie and Weatherhead 1988), then it may be argued that sundering should be more frequent when nestlings are older because the risk of losing a more valuable brood to the predator hurts parental fitness especially strongly. The hypothesis also predicts that sundering occurs before arriving at the nest to minimize time spent at the nest.

3. Hunting multiple prey hypothesis This hypothesis proposes that sundered prey is deposited on the ground while the bird searches for more earthworms and that sundered earthworms have a reduced ability to move away from the site at which they were deposited compared with the unsundered earthworms. Sundering prevents earthworms from escaping before they are loaded in the beak for transport, and temporary storing the prey on a ground makes foraging for new items more efficient, a feature expected from the optimal foraging theory (Schoener 1971; Charnov 1976; Pyke et al. 1977). The hypothesis predicts that sundering occurs before transporting the food to the nest rather than at the nest, and that sundering does not depend on the age of nestlings.

4. Transport of prey hypothesis This hypothesis proposes that when a long earthworm hangs down from the beak it may negatively affect the bird's flight/movements to the nest. This hypothesis predicts that the sundering will be performed before carrying the prey to the nest and that long earthworms will be sundered more often regardless of nestlings' age. Hypotheses (3) and (4) are difficult to distinguish based only on observational data.

None of these hypotheses are exclusive and all four mechanisms may operate in nature simultaneously. While a complete test of the hypotheses would require a series of experiments, our observational data may be used to determine the effects of nestlings' age and prey size on sundering, to determine where sundering is performed, and to discuss the evidence in light of those hypotheses. As time of day has been shown to affect passerine birds' feeding behavior (Pinkowski 1978; Johnson and Best 1982; Knapton 1984), and the duration of the inter-visit interval may be correlated with prey preparation (such as sundering) before visiting the nest, we have also statistically evaluated the effects of time of day, and inter-visit interval on sundering. Finally, as 
preparation of different prey taxa may be performed with different frequencies (Barba et al. 1996), we also considered that a taxonomic composition of the prey load may affect pitta's sundering behavior.

\section{Materials and methods}

\section{Field work}

From May to July in 2012, 2013, and 2017, we studied a total of 4 nests of the Fairy Pitta in Hallyeohaesang National Park located in the southern part of the Republic of Korea $\left(127^{\circ} 54^{\prime} \mathrm{E}, 34^{\circ} 50^{\prime} \mathrm{N}\right)$, which corresponds to the northern part of the Fairy Pitta's breeding range (Erritzoe 2020b). At each nest, we installed a dark-colored camouflaged tent $20 \mathrm{~m}$ away from the nest. From inside of the tent, we filmed and photographed visiting parents using digital cameras (Canon 1D Mark 4, Canon 7D, Canon 500D, lens Sigma 50-500 mm; Park 2014), details of recording time are shown in Tables S1, S2. Diet composition, visitation rates, and other ecological aspects related to the Fairy Pitta's conservation extracted from the collected material are addressed in Park et al. (own unpublished data). Here, we focus solely on the sundering behavior.

\section{Variables for statistical analyses}

We could not discriminate the visiting parent's sex. Therefore, the variables characterize a joint behavior of a pair of birds. From the observations, and from the videos and photographs, we extracted the following variables:

Nest ID We used four values for this categorical variable: nest 1 , nest 2 , nest 3 , and nest 4 . Each nest ID indicates a distinct nest, but as we observed 4 nests over 3 years, it is clear that variation among nests also embraces variation among years.

Visit ID Every visit is marked with a unique identifier among all visits observed in the four nests.

Nestlings' age The age of the nestlings in days from hatching. We assumed that on the date of hatching, the nestlings are 1 day old.

Nestling age class The age of the nestlings coded as "young" for 1-7-day-old brood, and "old" for 8-13-dayold brood.

Number of prey items The number of prey items brought by a parent in its beak at one visit (which constitutes a prey load). The two or more pieces of an earthworm were considered as one prey item (the same earthworm) based on the color, cross-section size, and shape.

Number of earthworms The number of earthworms brought by a parent in its beak at one visit.
Time of day This categorical variable has 3 values: morning (before $10 \mathrm{AM})$, noon (10 AM-2 PM), and afternoon (after 2 PM).

Feeding visit type For all feeding visits with earthworms present, each feeding visit was categorized as either the OE type of visit, in which only the earthworms were brought to the nestlings ("OE (Only Earthworms)") or the MIX type of visit, in which a mix of earthworms and other prey types were brought ("MIX").

Earthworm length category Earthworm length was categorized based on the average of all earthworms in all observed visits $(6.34 \pm 2.50 \mathrm{~cm}$; Park et al. own unpublished data). Earthworms longer than the average length were categorized as "long", and earthworms shorter than the average length were categorized as "short".

Prey sundering A binary variable with two values for each prey item: prey sundered or prey not sundered.

Sundered section length and Full length of prey A body length of each piece of prey (sundered section length, $\mathrm{cm}$ ) brought to the nest. We measured the length in the units of beak length and recalculated it to centimeters assuming beak length of $2 \mathrm{~cm}$ (Lin et al. 2007). Then, we calculated the full length of each sundered prey, matching two or more sections belonging to the same earthworm by the color, cross-section size, and shape.

Inter-visit interval Time between the previous feeding visit and the current feeding visit expressed in minutes and measured between the moment of leaving the nest and the moment of the subsequent arrival to the nest with food. We did not calculate the frequency of visits because our observations' starting and ending time was usually at the moment of a visit rather than at a pre-established moment independent of the timing of visits.

\section{Statistical analyses}

We used linear (lmer) and generalized ( $\mathrm{glmer}$ ) mixed-effects models to determine factors affecting the probability of prey sundering and explaining the variation of sundered section length and full length using lme4 package (Bates et al. 2015) and lmerTest package (Kuznetsova et al. 2017) in R version 4.0.2 (R Core Team 2020). To test for temporal autocorrelation in variables (i.e., the possibility that a variable value at a visit depends on its value at a previous visit, or two visits earlier or so), we used the acf function in $\mathrm{R}$ ( $\mathrm{R}$ core Team 2020), and we found no significant temporal autocorrelations. We used visit ID within a nest ID as a random variable in the statistical models. To attempt generalizations to a population of nests, we used the nest ID as a random variable. However, as there are only four levels of nest ID, using it as a random variable may be viewed as problematic. Therefore, we also used models with nest ID as an independent variable. The conclusions from these two types of analyses 
were very similar. In the analyses of the binary variable (i.e., prey sundering), we used statistical models with Binomial distribution. In the analyses of sundered section length and full length, the dependent variables were square-root transformed for normality, and we used normal distribution after checking that the assumptions are met. We tested for the normality of variables by the Shapiro-Wilk test.

As our goal was to analyze the handling of earthworms by the birds, we first focused on those visits in which a bird brought only earthworms to the nest (feeding visit type: $\mathrm{OE})$. As the data set for OE feeding visit type contained a very small sample of visits in the morning (one of three values of the variable: time of day), we excluded the time of day from the analyses performed on the data with $\mathrm{OE}$ visits only. We also conducted analyses for all visits that included earthworms (feeding visit types: OE and MIX), and in these analyses we included the time of day as one of the independent variables. As the inter-visit interval for the first feeding visit of each day could not be calculated, those data points were excluded from the analyses that included the inter-visit interval variable.

We used Akaike (AICc) criterion to choose the best model from a set (comprising the initial model and all models simpler than the initial one) generated and ranked by the dredge function in R (Bartoń 2020). However, considering a relatively small data set and the specific hypotheses, we chose to avoid initial models that may be too complex (e.g., due to the presence of interactions) and may lead to overparameterization. The effects considered in each initial model are listed in the captions of the tables with statistical results in the Online Resource 1 (Tables S3-S6). We tested multicollinearity between explanatory variables by vif using car package (Fox and Weisberg 2019) and found no serious concerns as the VIF and $\operatorname{GVIF}^{1 /(2 * D F)}$ were smaller than 1.15 in all models (Fox and Monette 1992; Kock and Lynn 2012).

\section{Results}

Based on direct observations and video recordings, a foraging pitta captured one earthworm at a time, put the single prey aside on the ground, and resumed searching for another prey, which was deposited at the same place on the ground. After multiple prey items have been collected on the ground, the bird picked up all of them and carried the full load to the nest (Online Resource 2), and fed the nestlings (Online Resource 3, 4). We often observed that the birds sundered earthworms into two or more pieces (Online Resource 2; Fig. 2A) before depositing them on the ground. We collected adequate data in two nests (nest 3 and nest 4 ) to precisely observe the effect of nestlings' age on prey sundering by parents: the frequency of prey sundering decreased with nestlings' age in both nests (Nest 3 : $r^{2}=0.45, p=0.016, y=-0.024 x+0.711$; Nest $4: r^{2}=0.586$, $p=0.016, y=-0.082 x+0.895$; Fig. 2C). The decrease in the percentage (\%) of earthworms sundered with nestlings' age was not gradual: a drop from $70-90 \%$ to $~ 20-40 \%$ occurred during $\sim 3$ days starting at the 4 th (Nest 4 ) or 6 th (Nest 3 ) day of nestlings' life (Fig. 2C).

The full length of unsundered earthworms was shorter than that of sundered earthworms (Fig. 2D; Table S3), and it was longer than the sundered section length of sundered earthworms (Fig. 2D; Table S3). The sundered section length was shorter when the nestlings were young (Fig. 2E; Table S3). Similar analysis and similar conclusions for nest ID used as an independent variable are presented in Table S4. In both analyses, the effect of nestling age class on the sundered section length was significant $(p<0.012)$. However, as the second best models in these analyses did not contain the effect of age (Table S3, S4) and differed little from the best ones ( $\triangle \mathrm{AICc}<0.9$ ), we cannot formally exclude the alternative interpretation of results that the nestling age does not affect the sundered section length.

As $41 \%$ of observed earthworms (223 out of total 547 earthworms) were sundered (Fig. 2A), whereas only $2 \%$ of the other prey ( 2 out of total 100 other prey items) were sundered, sundering behavior seems to be specific to earthworms as a prey. In total (feeding visit types: OE and MIX), 125 out of 256 long earthworms were sundered (about 49\%) while only 98 out of 291 short earthworms were sundered (about 34\%), indicating that longer earthworms were sundered more often. This was also confirmed by statistical analyses using generalized mixed models of the probability that an earthworm is sundered (Fig. 2G; Table S5). We statistically analyzed the occurrence of sundering (binary variable prey sundering: sundered or not) for all $\mathrm{OE}$ feeding visits (Table S5). We found out that parents sundered earthworms more often for younger nestlings (Fig. 2F), when earthworms were longer (Fig. 2G), and when the number of prey items was smaller (Fig. 2H). The effect of inter-visit interval on prey handling was marginally non-significant (Fig. 2I; Table S5). Similar analysis and similar conclusions for all visits that include at least one earthworm are present in Table S6. Observations from the field and from the videos indicated that when prey was relatively long, the smaller nestlings had difficulties swallowing it. In those cases, we observed that some adults took the prey out of the nestling's mouth and kept trying to give it to other nestlings (Online Resource 5). No quantitative data on these behaviors at the nest were collected.

\section{Discussion}

Our observations revealed that sundering occurs before transporting the earthworms to the nest, which may be consistent with all four hypotheses. Earthworm sundering 


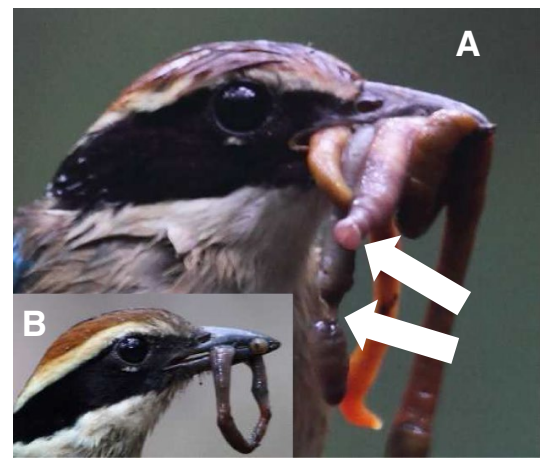

D
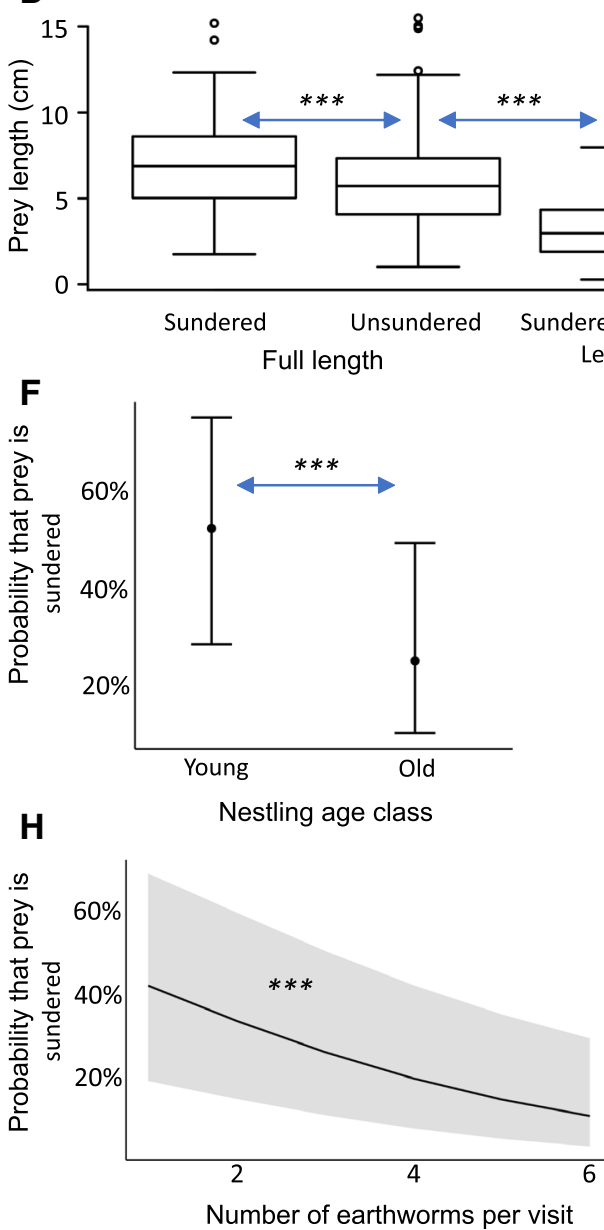

comprises simple prey-splitting behavior, and the Fairy Pittas brought all pieces at the same visit to the nest (JP personal observation). Our observations reveal that earthworm sundering has no direct relevance to the removal of certain body parts of prey, such as removing inedible parts of prey (Kaspari 1991; Sodhi 1992), and it does not have a function of making the prey load lighter to reduce the costs of prey transport (Sodhi 1992; Rands et al. 2000). As even long unsundered earthworms can be carried in a compact food load if they are bent and held by the beak at multiple points (e.g., Fig. 1B), the transport of prey hypothesis seems

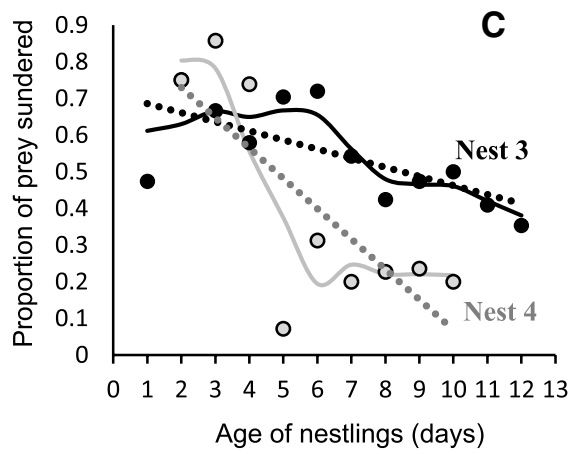

E
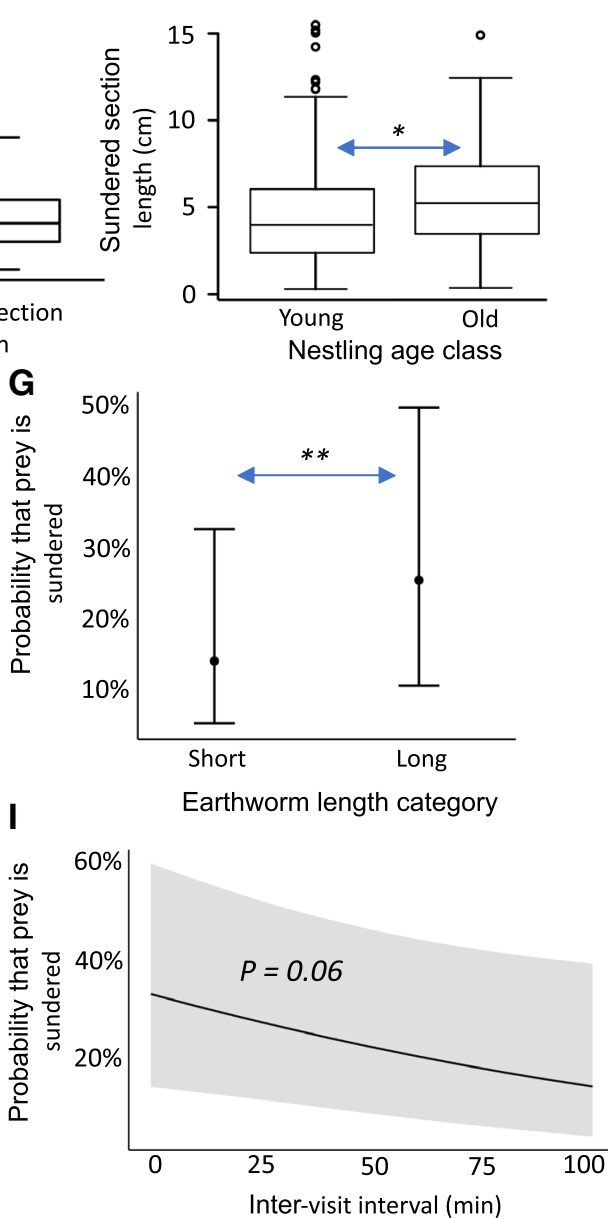

unlikely to be the sole explanation for earthworms sundering in the Fairly Pitta. The presence of the effect of nestling age on sundering is also inconsistent with transport of prey mechanism, which does not predict such an effect. However, we cannot entirely reject this hypothesis based only on our observational data.

The observation that longer worms were more likely to be sundered than the smaller ones may be viewed as inconsistent with the "hunting of multiple prey" hypothesis because the ability of a worm to escape from a pile of worms may not necessarily be dependent on the worm size, but if it does 
4Fig. 2 Earthworm sundering behavior by the Fairy Pitta. A the Fairy Pitta with a load of earthworms brought to nestlings (arrows indicate the places where the earthworm was sundered; occasionally sundering is not complete as indicated by the lower arrow). B The Fairy Pitta with an earthworm that is not sundered and has been bent, and is held in a beak by its two ends. C Effect of nestlings' age (days from hatching) on the probability of sundering in two nests with the most detailed daily observations; as this data are from only two nests, we did not analyze them statistically and presented them to hypothesize about a possible nest-specific "switch" from frequent sundering to less frequent sundering with an increase in nestlings age. D Full length $(\mathrm{cm})$ of sundered and unsundered earthworms, and the sundered section length of sundered earthworms; statistical analysis in Table S3. E Effect of nestling age class on sundered section length; statistical analysis in Table S3. F Effect of nestling age class (young vs. old) on the probability of sundering; statistical analysis in Table S5; G effect of earthworm length category (short vs. long) on the probability of sundering; statistical analysis in Table S5; H Effect of number of earthworms in a load brought to the nest at a visit on the probability of sundering; statistical analysis in Table S5; I effect of inter-visit interval preceding the visit to the nest on the probability of sundering; statistical analysis in Table S5. A horizontal thick line indicates the median, the box indicates the 1st (lower, Q1) quartile and 3rd (upper, Q3) quartiles, the error bars (vertical lines) indicate the 1.5 interquartile range, the extra data points are outliers defined as data points that are located outside the 1.5 times the interquartile range above the upper quartile and below the lower quartile $(\mathbf{D} ; \mathbf{E})$. Dots $(\mathbf{F} ; \mathbf{G})$ and a curved line $(\mathbf{H} ; \mathbf{I})$ indicate predicted probabilities of sundering, and vertical lines $(\mathbf{F} ; \mathbf{G})$ and gray-shaded area $(\mathbf{H} ; \mathbf{I})$ represent $95 \%$ confidence intervals. $*$ indicates $p<0.05$; $* *$ indicates $p<0.01$; *** indicates $p<0.001$. Photos in $\mathbf{A}$ and $\mathbf{B}$ are taken by the first author. Full statistical analyses are presented in the Online Resource 1: Table S3 (for panels D, E), and Table S5 (for panels $\mathbf{F}-\mathbf{I}$ )

then it is more likely that the smaller worm may be quicker at moving away and disappearing from the field of view among leaf litter on the ground than the larger one. Nevertheless, as the handling of a detected and attacked earthworm is clearly easier and more efficient when no other food items are held in the beak, it seems beneficial for pittas to deposit their prey items (earthworms) at one spot on the ground instead of carrying them in the beak while foraging (see Online Resource 2). These observations appear to be partly consistent with the idea that the function of prey depositing may be an increase in foraging efficiency, and that the function of prey sundering may be to reduce the prey's mobility and to decrease the risk that prey will escape after being deposited on the ground. Experiments on earthworm mobility and foraging efficiency of pittas are needed to fully evaluate this hypothesis.

The results also revealed that the sundered worms were more often delivered to young rather than to old nestlings and that sundered sections were shorter when nestlings were younger. As one of the predictions from the "decreased detectability hypothesis" is more frequent sundering when the brood is older, it appears that this hypothesis alone cannot fully explain the observed pattern. The significantly higher frequency of sundering prey and shorter sundered section length for younger nestlings, who were observed to have difficulties swallowing large items, are all consistent with the provisioning of small nestlings hypothesis, and are reminiscent of results from other species of birds that do not feed their nestlings with earthworms (e.g., Barba et al. 1996; Banbura et al. 1999). The relatively abrupt decrease in sundering during $~ 3$ days starting on the 4th (Nest 4) or 6th (Nest 4) day of nestlings' life (Fig. 2C) is consistent with the idea that after a specific growth stage is reached, the nestlings may be able to swallow most of the unsundered earthworms. This hypothetical stage may correspond to the slowdown of body mass growth and the increase in the growth rate of feathers as suggested by Jiang et al. (2017), who observed that the feathers on wings, back, and head of nestlings start growing at the age of about 7 days after hatching. However, to further evaluate the feasibility of this hypothetical threshold, detailed data are needed for many more nests.

The lack of significant effects of time of day and intervisit interval on sundering and on the prey length (albeit the non-significant effects may be included in the top models) do not contradict any of the four hypotheses. As each piece of a sundered worm has to be kept in the beak separately during transport, it is obvious that sundered worms were more often observed in loads of fewer worms. As it presumably takes less time to collect a load of fewer worms, we expected a negative relationship between the inter-visit interval and the probability of earthworm sundering. The results partly suggest such an effect: the best model included marginally non-significant $(p=0.060)$ effect of inter-visit interval (albeit the second best model without this effect did not differ dramatically in the fit to the data from the best model: $\Delta \mathrm{AICc}=1.56$ in Table S5).

Trade-offs may exist between costs of prey preparation to parents and benefits to the nestlings from being fed the prepared prey (Ponz et al. 1999), as well as between costs of prey preparation versus costs for carrying unprepared prey (Rands et al. 2000). However, our observations indicate that the act of sundering of an earthworm (unlike preparing a prey with a hard exoskeleton) is quick and easy i.e., not costly in terms of handling time or energy. Therefore, the aforementioned tradeoffs may not directly apply to the Fairy Pitta and possibly other vermivores who sunder earthworms.

In summary, this is the first quantitative analysis of the specific prey preparation behavior known to occur in avian vermivores provisioning their broods: earthworm sundering. Although our observational data and preliminary analyses do not completely allow us to reject any of the four hypotheses considered, we suspect that the main function of sundering by the Fairy Pitta is to increase the probability that a nestling is able to quickly swallow the prey. More extensive data collection from various avian vermivores, such as pittas, antpittas, or thrushes is needed to understand the general 
adaptive explanations for earthworm sundering, an understudied method of prey preparation by parent birds.

Supplementary Information The online version contains supplementary material available at https://doi.org/10.1007/s10336-021-01955-0.

Acknowledgements JS sincere thanks to Sung-lae Jang (Korea National Park Service) for introducing territories of the Fairy Pitta. We thank The Macaulay Library at the Cornell Lab of Ornithology for letting us use photos from their digital archives. During preparation of the manuscript, authors were supported by BK21 Programme to the School of Biological Sciences at the Seoul National University, NRF grant no. 2019R1A2C1004300, DGIST Start-up Fund Program nr 20200810 of the Ministry of Science, ICT and Future Planning of Korea, and the 2019-2020 Convergence Research Grant from the Seoul National University. The authors declare the field observation comply with the current laws of South Korea.

Author contributions Conceptualization: [SL, PGJ]; data curation: [JP]; formal analysis: [JP, WK, JH, SL, PGJ]; funding acquisition: [SL, PGJ]; investigation: [JP]; methodology: [JP]; project administration: [SL, PGJ]; supervision: [SL, PGJ]; validation: [SL, PGJ]; visualization: [JP, WK, SL, PGJ]; writing —original draft: [JP]; writing—review and editing: [JP, WK, JH, SL, PGJ].

Funding Authors were supported by the Seoul National University, NRF, DGIST Start-up Fund of the Ministry of Science.

Availability of data and material Data supporting the results are available from the Figshare at: https://doi.org/10.6084/m9.figshare.14390 903.v3 Prey length data can be requested from the first author.

Code availability Not applicable.

\section{Declarations}

Conflict of interest The authors declare that they have no known competing financial interests or personal relationships that could have appeared to influence the work reported in this paper.

Ethics approval No animals were captured, harmed, or stressed in any way during this study. Observations of birds were conducted with the knowledge and assistance from the Hallyeohaesang National Park.

Consent to participate Not applicable.

Consent for publication Not applicable.

Open Access This article is licensed under a Creative Commons Attribution 4.0 International License, which permits use, sharing, adaptation, distribution and reproduction in any medium or format, as long as you give appropriate credit to the original author(s) and the source, provide a link to the Creative Commons licence, and indicate if changes were made. The images or other third party material in this article are included in the article's Creative Commons licence, unless indicated otherwise in a credit line to the material. If material is not included in the article's Creative Commons licence and your intended use is not permitted by statutory regulation or exceeds the permitted use, you will need to obtain permission directly from the copyright holder. To view a copy of this licence, visit http://creativecommons.org/licenses/by/4.0/.

\section{References}

Banbura J, Lambrechts MM, Blondel J et al (1999) Food handling time of blue tit chicks: constraints and adaptation to different prey types. J Avian Biol 30:263-270. https://doi.org/10.2307/3677352

Barba E, López JA, Gil-Delgado JA (1996) Prey preparation by adult Great Tits Parus major feeding nestlings. Ibis (lond 1859) 138:532-538. https://doi.org/10.1111/j.1474-919x.1996.tb080 74.x

Bartoń K (2020) MuMIn: multi-model inference. R package version 1.43.17. https://CRAN.R-project.org/package=MuMIn

Bates D, Mächler M, Bolker BM, Walker SC (2015) Fitting linear mixed-effects models using lme4. J Stat Softw. https://doi.org/ 10.18637/jss.v067.i01

Charnov EL (1976) Optimal foraging, the marginal value theorem. Theor Popul Biol 9:129-136. https://doi.org/10.1016/00405809(76)90040-X

Collar N (2020) Fieldfare (Turdus pilaris), version 1.0. In: del Hoyo J, Elliott A, Sargatal J, Christie DA, de Juana E (eds) Birds of the world. Cornell Lab Ornithol, Ithaca. https://doi.org/10.2173/ bow.fieldf.01

Collar N, Christie DA, Kirwan GM, del Hoyo J (2020) Scaly Thrush (Zoothera dauma), version 1.0. In: Billerman SM, Keeney BK, Rodewald PG, Schulenberg TS (eds) Birds of the world. Cornell Lab Ornithol, Ithaca. https://doi.org/10.2173/bow.scathr8.01

del Hoyo J, Collar N, Sharpe CJ, Christie DA (2020) Amami Thrush (Zoothera major), version 1.0. In: del Hoyo J, Elliott A, Sargatal J, Christie DA, de Juana E (eds) Birds of the world. Cornell Lab Ornithol, Ithaca. https://doi.org/10.2173/bow.scathr6.01

Erritzoe J (2020a) Blue-winged Pitta (Pitta moluccensis), version 1.0. In: del Hoyo J, Elliott A, Sargatal J, Christie DA, de Juana E (eds) Birds of the world. Cornell Lab Ornithol, Ithaca. https://doi.org/ 10.2173/bow.blwpit1.01

Erritzoe J (2020b) Fairy Pitta (Pitta nympha), version 1.0. In: del Hoyo J, Elliott A, Sargatal J, Christie DA, de Juana E (eds) Birds of the world. Cornell Lab Ornithol, Ithaca. https://doi.org/10.2173/ bow.faipit1.01

Fox J, Monette G (1992) Generalized collinearity diagnostics. J Am Stat Assoc 87:178-183. https://doi.org/10.1080/01621459.1992. 10475190

Fox J, Weisberg S (2019) An R companion to applied regression, Third editorr. Sage, Thousand Oaks

Futuyma DJ, Moreno G (1988) The evolution of ecological specialization. Ann Rev Ecol Syst 19:207-233. https://doi.org/10.1146/ annurev.es.19.110188.001231

Gruar D, Peach W, Taylor R (2003) Summer diet and body condition of Song Thrushes Turdus philomelos in stable and declining farmland populations. Ibis (lond 1859) 145:637-649. https://doi. org/10.1046/j.1474-919X.2003.00202.x

Irschick D, Dyer L, Sherry TW (2005) Phylogenetic methodologies for studying specialization. Oikos 110:404-408. https://doi.org/ 10.1111/j.0030-1299.2005.13927.x

Jiang A, Yang G, Pagani-Núñez E, Jiang D (2017) Ecology of two Pittas (Pitta soror and Pitta nympha) in limestone forests of South China. J Nat Hist 51:1929-1941. https://doi.org/10.1080/00222 933.2017.1355490

Johnson EJ, Best LB (1982) Fators affecting feeding and brooding of gray catbird netlings. Auk 99:148-156

Kaspari M (1990) Prey preparation and the determinants of handling time. Anim Behav 40:118-126. https://doi.org/10.1016/S00033472(05)80671-2

Kaspari M (1991) Prey preparation as a way that Grasshopper Sparrows (Ammodramus svannarum) increase the nutrient content concentration of their prey. Behav Ecol 2:234-241. https://doi.org/10. 1093/beheco/2.3.234 
Kim E-M, Park C-R, Kang C-W, Kim S-J (2012) The nestling diet of fairy pitta pitta nympha on Jeju Island, Korea. Open J Ecol 02:178-182. https://doi.org/10.4236/oje.2012.24021

Knapton RW (1984) Parental feeding of nestling Nashville Warblers: the effects of food type, brood-size, nestling age, and time of day. Wilson Ornithol Soc 96:594-602

Kock N, Lynn GS (2012) Lateral collinearity and misleading results in variance-based SEM: an illustration and recommendations. $\mathbf{J}$ Assoc Inf Syst 13:546-580. https://doi.org/10.17705/1jais.00302

Kuznetsova A, Brockhoff PB, Christensen RHB (2017) lmerTest package: tests in linear mixed effects models. J Stat Softw 82:1-26. https://doi.org/10.18637/jss.v082.i13

Lin R, Yao C, Lee P (2007) The diet of fairy pitta pitta nympha nestlings in taiwan as revealed by videotaping. Zool Stud 46:355-361

Lopes LE, Fernandes AM, Medeiros MCI, Marini MÂ (2016) A classification scheme for avian diet types. J F Ornithol 87:309-322. https://doi.org/10.1111/jofo.12158

Montgomerie RD, Weatherhead PJ (1988) Risks and rewards of nest defence by parent birds. Q Rev Biol 63:167-187. https://doi.org/ $10.1086 / 415838$

Montgomerie R, Weatherhead PJ (1997) How robins find worms. Anim Behav 54:143-151. https://doi.org/10.1006/anbe.1996.0411

Park J (2014) Parenting secret of fairy pitta. Nature and human, South Korea

Park J, Ha J, Kim W, Lee S-I, Jablonski PG (2021) Nestling diet and parental provisioning in the endangered Fairy Pitta (Pitta nympha), and their possible implications for conservation. (own unpublished data)

Pinkowski BC (1978) Feeding of nestling and fledgling eastern bluebirds. Wilson Bull 90:84-98

Ponz A, Gil-Delgado JA, Barba E (1999) Factors affecting prey preparation by adult Magpies feeding nestlings. Condor 101:818-823. https://doi.org/10.2307/1370069

Pyke GH, Pulliam HR, Charnov EL (1977) Optimal foraging: a selective review of theory and tests author(s). Q Rev Biol 52:137-154. https://doi.org/10.1086/409852
R Core Team (2020) A language and environment for statistical computing. R Foundation for Statistical Computing

Rands SA, Houston AI, Gasson CE (2000) Prey processing in central place foragers. J Theor Biol 202:161-174. https://doi.org/10.1006/ jtbi.1999.104

Schoener TW (1971) Theory of feeding strategies. Annu Rev Ecol Syst 2:369-404. https://doi.org/10.1146/annurev.es.02.110171.002101

Schulenberg TS, Kirwan GM (2020) Moustached Antpitta (Grallaria alleni), version 1.0. In: Schulenberg TS (Ed) Birds of the world. Cornell Lab Ornithol, Ithaca. https://doi.org/10.2173/bow.mouan t1.01

Sodhi NS (1992) Central place foraging and prey preparation by a specialist predator, the Merlin. J F Ornithol 63:71-76

Steen R, Løw LM, Sonerud GA, Selås V, Slagsvold T (2010) The feeding constraint hypothesis: prey preparation as a function of nestling age and prey mass in the Eurasian kestrel. Anim Behav 80:147-153. https://doi.org/10.1016/j.anbehav.2010.04.015

Vanderhoff N, Pyle P, Patten MA, Sallabanks R, James FC (2020) American robin (Turdus migratorius), version 1.0. In: Rodewald PG (ed) Birds of the World. Cornell Lab Ornithol, Ithaca. https:// doi.org/10.2173/bow.amerob.01

Winkler DW (1987) A general model for parental care. Am Nat 130:526-543. https://doi.org/10.1086/284729

Winkler DW, Billerman SM, Lovette IJ (2020) Pittas (Pittidae), version 1.0. In: Billerman SM, Keeney BK, Rodewald PG, Schulenberg TS (eds) Birds of the world. Cornell Lab Ornithol, Ithaca. https:// doi.org/10.2173/bow.pittid1.01

Publisher's Note Springer Nature remains neutral with regard to jurisdictional claims in published maps and institutional affiliations. 